\title{
Quantitative determination of ciprofloxacin and levofloxacin antibacterials by Spectrophotometeric and high performance liquid chromatography
}

\author{
Muhammad Akram ${ }^{1}$, Jamil Anwar ${ }^{2}$, Ammar Z. Alshemary ${ }^{1}$, Yi-Fan Goh ${ }^{1}$, Ahmed Sher Awan ${ }^{3}$ and Qamar H. Farooqi ${ }^{4}$ \\ ${ }^{1}$ Department of Chemistry, Universiti Teknologi Malaysia, 81310 UTM Skudai, Johor Darul Ta'zim, Malaysia \\ ${ }^{2}$ Garrison University, Defence Phase VI, Lahore, Pakistan \\ ${ }^{3}$ Department of Science Education (IER), Quaid-i-Azam Campus University of Punjab, Lahore, Pakistan \\ ${ }^{4}$ Department of Chemistry, Quaid-i-Azam Campus University of Punjab, Lahore, Pakistan \\ *Corresponding Author: akramrajajang@gmail.com
}

\section{Article history :}

Received 1 September 2014

Accepted 11 February 2015

\section{GRAPHICAL ABSTRACT}

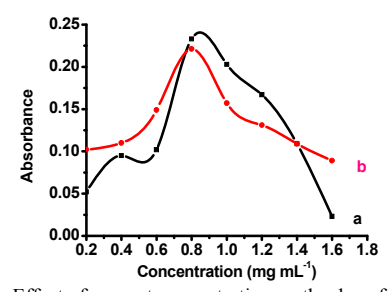

Effect of reagent concentration on the drug-ferric (III) complex

\begin{abstract}
A simple, rapid and sensitive Spectrophotometeric method for the determination of fluoroquinolones; ciprofloxacin and levofloxacin have been performed in pure form and pharmaceutical tablets. Both drugs gave reddish complexes when treated with iron (III) chloride at $\mathrm{pH}$ 4.0. The drugs showed maximum absorption at 530 and $545 \mathrm{~nm}$. In both cases linear calibration was obtained up to $0.9 \mathrm{mg} / 10$ $\mathrm{mL}$ of the drug. Effect of different parameters like $\mathrm{pH}$, temperature and time was also studied on the stability of the complexes. The percentage recoveries found by described method was in the range of 98.2---100.01 \%. Standards were prepared from the pure compounds obtained from sigma-Aldrich Pharm. The method was successfully employed for the Assay of drugs in commercial formulations. Finally determination of the drugs was carried out through HPLC method which showed that there is no appreciable difference between the results of both the methods. Results revealed that proposed method is practically suitable for routine applications in quality control laboratories for the analysis of fluoroquinolones drugs.
\end{abstract}

Keywords: fluoroquinolones, ciprofloxacin, levofloxacin, spectrophotometery and HPLC

\section{INTRODUCTION}

Quinolones antibacterial drugs are in use since 1963 when Nalidixic acid was approved by the FDA and since then are available for the treatment of different infectious diseases [1,2]. It is rapidly absorbed after oral administration and has long half-life and is easily excreted into the Urine [3]. This drug has several limitations, which limits its use in other type of infections especially Nalidixic acid has limited activity and microorganisms easily develop resistance to this drug [1].

Quinolone based antibacterial drugs encompass an interesting group of anti-bacterial drugs whose primary target is to destroy bacterial DNA gyrase and topoisomerase IV [4,5]. During 1980's modifications of this drug based on structure activity-relationships were made. It had been discovered that their anti-bacterial activity can be increased by the incorporation of a fluorine atom on the number 6-carbon atom and a piperazine ring at the number 7 carbon atom. This modified drug was given the name fluoroquinolones group and are found active against gram +ve organisms and the gram -ve bacterial infections. Thus these newer fluoroquinolones antibiotics are extremely useful in a variety of infections like soft tissue infections, respiratory infections, bonejoint infections, typhoid fever and acute bronchitis.

Ciprofloxacin and levofloxacin antibacterials are important anti-bacterial drugs with fluorine atom on the number 6-carbon atom of the naphthyridine ring and according to the literature this substitution has broadened their activity spectrum against both gram +ve and gram ve pathogens $[6,7]$. Owing to their wide use against different infectious diseases many methods are available for their identification which include several analytical methods like capillary electrophoresis [8,9] and high performance liquid chromatography (HPLC) [10,11]. Although HPLC is the widely employed method for the quantitative determination of fluoroquinolones but its complex procedure, multistep and cost made it unpopular. Spectrophotometer method is the cost effective and single step method for the quantitative determine of fluoroquinolones drugs.

In present research investigation a simple and single step spectrophotometer method has been adopted for the quantitative determination of ciprofloxacin and levofloxacin in the pure form and in the assay of drugs in the commercial formulations by making its complexes with iron (III) chloride. Finally the results were compared through HPLC determination method so as to validate the Spectrophotometeric method results, which confirmed that there is no major difference between the results obtained through both of the methods.

\section{EXPERIMENTS}

\section{$2.1 \quad$ Instrumentation}

All absorbance measurements were conducted with a double beam UV-1800 (SHIMADZU, Japan) ultraviolet-visible spectrophotometer provided with 
quartz cells having thickness around 1-cm. During all spectrophotometeric measurements temperature controller was used to maintain the temperature.

\subsection{Chemicals and Reagents}

All regents and solvents were of analytical grade and were used without further purification. Dodecyl sodium sulphate $(0.24 \%)$, acetonitrile and Glacial acetic acid, ferric (III) chloride hydrochloric acid and phosphoric acid were obtained from Merck. Ciprofloxacin (CIP) and Levofloxacin (LEV) tablets were purchased from the local market. Brand names of tablets and name of companies are given below.

Table 1 Commercial pharmaceutical dosage form samples of ciprofloxacin used in the research.

\begin{tabular}{lll}
\hline Sample ID & Brand name & Manufacturer Name/dosage \\
\hline CIP-PP-a & Ciplox & $\begin{array}{l}\text { Pharmadic Pharmaceuticl (PVT) } \\
\text { ltd/250 mg }\end{array}$ \\
CIP-HP-b & Hiflox & $\begin{array}{l}\text { Hilton Pharma (PVT)/250 mg } \\
\text { CIP-SP-c }\end{array}$ \\
& Novidate & $\begin{array}{l}\text { Sami Pharmaceutical (PVT) } 1 \mathrm{td} / 250 \\
\mathrm{mg}\end{array}$ \\
\hline
\end{tabular}

Table 2 Commercial pharmaceutical dosage form samples of levofloxacin used in the research.

\begin{tabular}{|c|c|c|}
\hline Sample ID & Brand name & Manufacturer Name/dosage \\
\hline LEV-GP-d & Levolfox & Getz Pharima (PVT) Ltd./250 mg \\
\hline LEV-OP-e & Everbact & $\begin{array}{l}\text { Obson Pharmaceutical industries } \\
\text { (PVT) Ltd. } / 250 \mathrm{mg}\end{array}$ \\
\hline LEV-TP-f & Pelikan & $\begin{array}{l}\text { Tegma Pharmaceutical Labs (PVT) } \\
\text { Ltd. } / 250 \mathrm{mg}\end{array}$ \\
\hline
\end{tabular}

The active pharmaceutical ingredients (API) which include CIP and LEV were purchased from sigmaAldrich Pharm and used as reference standards without further purification.

\subsection{Preparation of stock and sample solutions}

All reagents and stock solutions required were prepared in $0.02 \mathrm{M} \mathrm{HCl}$ and doubly distilled water. 1.0 gram of pure drug (CIP and LEV) was dissolved in 0.02 $\mathrm{M} \mathrm{HCl}$ in $1000 \mathrm{ml}$ measuring flask. The contents were dissolved and swirled well then volume was made up to the mark. This stock solution was filtered and further dilutions were prepared from this stock solution. This solution was kept in dark in air tight container. 8.0 gram of ferric chloride was dissolved in $100 \mathrm{ml}$ doubly distilled water in $100 \mathrm{ml}$ measuring flask and volume was made up to mark and was used as complexing agent.

Eight tablets of each company equal to $2000 \mathrm{mg}$ (250 mg x 8) were ground to fine powder using pestle and mortar. The total contents were accurately weighed again. From this powder weight equivalent to 1.0 gram was dissolved in $0.02 \mathrm{M} \mathrm{HCl}$ in $1000 \mathrm{ml}$ measuring flask to get a stock solution of $1000 \mathrm{ppm}$. This solution was then filtered and kept in dark for the quantitative analysis of the commercial pharmaceutical formulations.

2.4. General Procedure for the reaction of Ciprofloxacin and Levofloxacin with ferric (III) chloride (Selection of analytical wave length)

CIP and LEV react with ferric chloride to give red colour complex. This reaction is specific for fluoroquinolones hydrochlorides and thus provides a base for spectrophotometeric method for the determination of fluoroquinolones in pure form and in tablets. To an aliquot $(3 \mathrm{ml})$ of each drug (CIP and LEV) containing 0.5 to $9.0 \mathrm{ug} / \mathrm{ml}$ was added to $3.0 \mathrm{ml}$ of ferric chloride solution. A red colour complex is instantly formed which was diluted up to $10 \mathrm{ml}$ with distilled water. All complexes were allowed to stand at room temperature $\left(25 \pm 5^{\circ} \mathrm{C}\right)$ for half an hour to check the stability of the complex. Finally absorbance measurement of CIP and LEV complexes were taken as to select the analytical wave length $(\lambda \max )$ for the both of the complexes and were observed at $530 \mathrm{~nm}$ for CIP and $545 \mathrm{~nm}$ for LEV complex (fig. $\mathbf{1}$ a and b). All the absorbance measurements were made against the reagent blank prepared in the same manner using $3 \mathrm{~mL}$ water instead of $3 \mathrm{~mL}$ ferric chloride solution. At the end effect of ferric chloride concentration and temperature on the stability of the complex was studied.
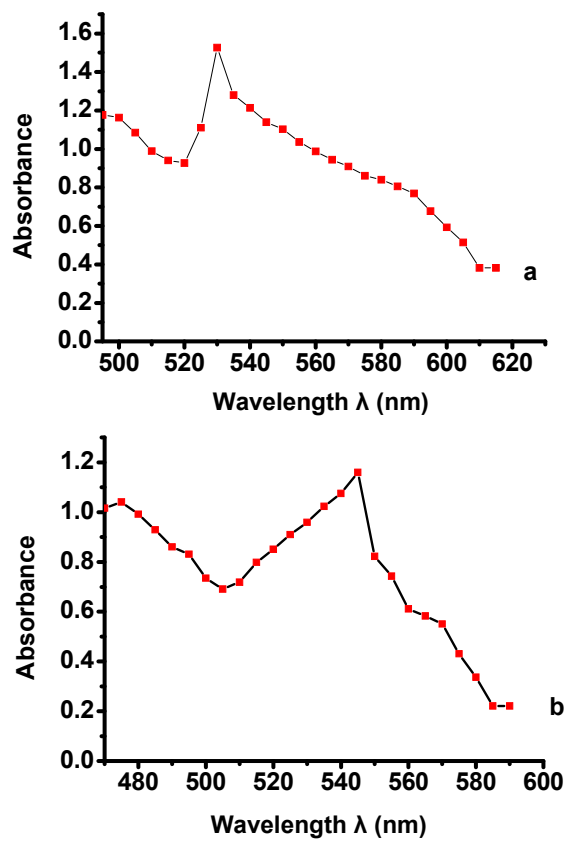

Figure 1. (a) Measurement of the $\lambda \max$ for CIP and (b) showing the measurement of the $\lambda \max$ for LEV.

\subsection{Optimization studies of reaction variables}

\subsubsection{Effect of $\mathrm{pH}$}

The effect of $\mathrm{pH}$ was studied in the $\mathrm{pH}$ range 2.0 5.5. Results are shown in the figure 2 which have illustrated that drug-metal complexes in both cases give maximum absorbance at $\mathrm{pH} 4$. Owing to this reason all measurements were carried out using buffer of $\mathrm{pH} 4$.

\subsubsection{Effect of temperature and time on the complex}

The effect of temperature was studied at 30, 40, $50,60,70,80$ and $90{ }^{\circ} \mathrm{C}$. The temperature was maintained for 5 and $10 \mathrm{~min}$. The solutions were then cooled in ice bath and absorbance was recorded at 530 and $545 \mathrm{~nm}$. The results are shown in the figure 3 . 


\subsubsection{Effect of ferric (III) chloride concentration on the complex}

Preliminary experiments were performed to fix the optimum concentrations of the ferric (III) chloride that could be used for the spectrophotometeric determination of CIP and LEV and this was found to be $0.08 \mathrm{mg} \mathrm{mL}^{-1}$.

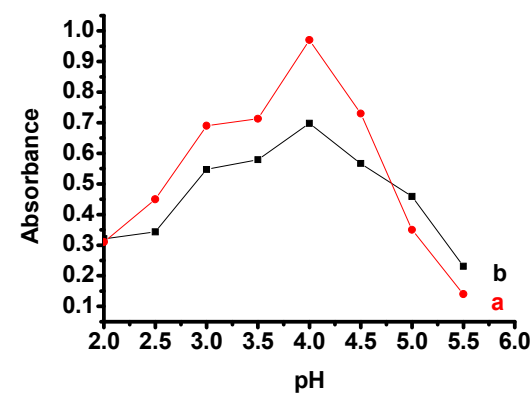

Figure 2. Effect of $\mathrm{pH}$ on the drug-ferric (III) complex (a) CIPcomplex and (b) LEV-complex.

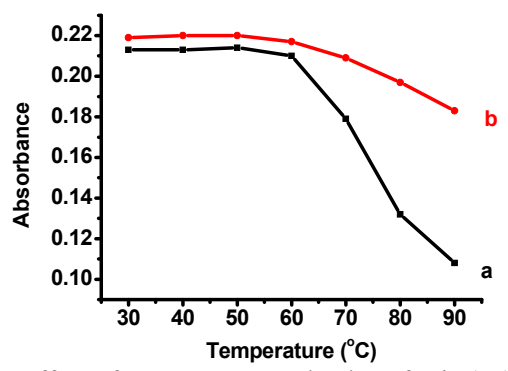

Figure 3. Effect of temperature on the drug-ferric (III) complex (a) CIP-complex and (b) LEV-complex.

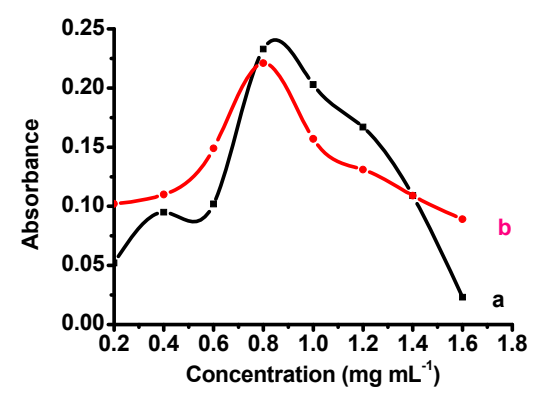

Figure 4. Effect of reagent concentration on the drug-ferric (III) complex.

\subsubsection{Validation Studies}

Linearity of response for each drug (CIP and LEV) for the reaction with ferric (III) chloride using the range of $0.05-0.9 \mu \mathrm{g} \mathrm{mL}-1$ from the drug stock solution in 0.02 $\mathrm{M} \mathrm{HCl}$ was prepared. For CIP the absorbance was taken at $530 \mathrm{~nm}$ while for LEV was taken at $545 \mathrm{~nm}$ (fig. 5). While the absorbance difference between ferric (III) chloride alone and ferric (III) chloride with both of the drugs was also recorded. Linear regression analysis was used to select the dynamic working range. Replicate samples were prepared for the calibration. The regression line equation, correlation coefficient and limit of detection were obtained from the calibration curve.

The precision of the method was assessed using replicate samples of the drugs at different concentration levels within the $0.05-1.0 \mathrm{ug} \mathrm{mL}-1$ concentration range.
Each concentration of the drug was reacted with ferric (III) chloride and absorbance was recorded using optimized reaction conditions at 530 and $545 \mathrm{~nm}$. The concentration of the drugs was estimated from the regression line equation. The precision was thereafter determined with percent relative standard deviation (\% coefficient of variation).

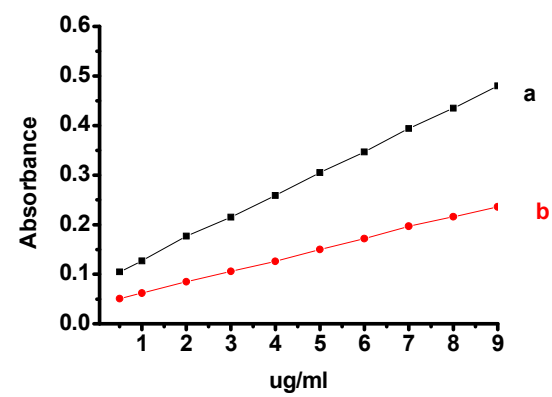

Figure 5. Calibration curve for (a) CIP and (b) LEV.

\subsubsection{Dosage forms Analysis}

Three different brands of CIP and LEV tablets were evaluated for their content of active ingredient by using this spectrophotometeric method. Weight uniformity test was carried out on each brand of the tablets. Eight (08) tablets were crushed and powdered. Form the $1000 \mathrm{ppm}$ stock solution prepared a working concentration of $10 \mathrm{ppm}$. To $3.0 \mathrm{ml}$ of this drug solution was added $3.0 \mathrm{ml}$ of colouring reagent and diluted the volume up to $10.0 \mathrm{ml}$ with distilled water. The absorbance was measured at 530 and $545 \mathrm{~nm}$. The concentration corresponding to the measured absorbance was determined using the regression line equation. The amount of drug determined by this method was compared with the amount of drug present in different commercial pharmaceutical formulations. Finally $\%$ age error was calculated.

\subsubsection{Interference studies}

$3 \mathrm{ml}$ of drug solution was mixed with $3 \mathrm{ml}$ of colouring reagent. And then this reference solution was mixed with $10 \mathrm{mg}$ quantities of common excipients such as lactose, starch and talc and allowed to stay for 15 minutes Then analyses of these laboratory prepared samples were carried out using the general procedure and the recoveries were evaluated, showing no appreciable effect on the absorbance.

\section{RESULTS AND DISCUSSION}

CIP and LEV drugs belong to fluoroquinolones group antibiotics. These are insoluble in water but soluble in ethanol, methanol, chloroform and in acids like hydrochloric acid, sulphuric acid and acetic acid. These drugs have two functional groups: an ionisable carboxylic group pka 6.05 and pka 5.05 [12] and a piperanyzyl group pka 8.22 and pka 7.90. These two drugs show absorption maxima in the visible region at 530 and $545 \mathrm{~nm}$ (fig. 1). The fluorine atom present in the quinolones group act as an electron withdrawing group, the benzene ring in the two drugs has lower electron density than the terminal 
nitrogen atom in the piperazinyl moiety. So these drugs serve as n-electron donors to form complexes with metals [13]. This finding supports that the interaction of these two drugs and reagent takes place at only one site which is the $\mathrm{N}$-atom of piperazinyl ring considering the steric and electron donating factors.

This method was successfully applied for the spectrophotometeric determination CIP and LEV. Results have indicated that metal-drug complexes showed maximum absorption at $\mathrm{pH} 4$ (fig. 2) which confirms that $\mathrm{pH} 4$ is the best working range for these complexes. Similarly results shown in the figure 3 illustrated that complexes are stable at ambient temperature and showed stability up to $60{ }^{\circ} \mathrm{C}$. All spectrophotometeric measurements confirmed that these complexes obey Beer's law (fig. 5) and give linear line and allow the way to determine the amount of drug in the concentration range $0.5-0.9 \mathrm{ug} / \mathrm{ml}$. This method was then successfully applied for the determination of drugs in pure samples as shown in the table 3 which show reproducibility, sensitivity and validity of the method. This colorimetric method was then successfully applied for quantitative determine of the amount of drug in different commercial formulations. These results are given below in the table 4 and 5 for each drug.

Table 3 Amount of drugs determined in pure drugs.

\begin{tabular}{lclll}
\hline Sample & $\begin{array}{l}\text { Amount } \\
\text { taken } \\
\mathbf{m g} / \mathbf{1 0} \\
\mathbf{~ m L}\end{array}$ & $\begin{array}{l}\text { Amount } \\
\text { found } \\
\mathbf{m g} / \mathbf{1 0} \mathbf{~ m L}\end{array}$ & $\begin{array}{l}\text { Recovery } \\
\mathbf{( \% )}\end{array}$ & $\begin{array}{l}\text { Relative } \\
\text { standard } \\
\text { deviation } \\
\mathbf{( \% )}\end{array}$ \\
\hline CIP-HCl & 0.1 & 0.0997 & 99.7 & 0.19 \\
& 0.3 & 0.2998 & 99.9 & 0.23 \\
& 0.5 & 0.4995 & 99.9 & 0.50 \\
& 0.7 & 0.7001 & 100.01 & 0.27 \\
\hline Mean + SD & 0.9 & 0.8945 & 99.4 & 0.52 \\
\hline LEV-HCl & 0.1 & 0.0999 & $99.70 \pm 0.64$ & \\
& 0.3 & 0.2996 & 99.8 & 0.35 \\
& 0.5 & 0.494 & 98.8 & 0.41 \\
& 0.7 & 0.699 & 99.8 & 0.22 \\
& 0.9 & 0.9001 & 100.01 & 0.29 \\
\hline Mean + SD & & & $99.70 \pm 0.64$ & \\
\hline
\end{tabular}

Table 4 Amount of ciprofloxacin determined spectrophotometerically.

\begin{tabular}{lccl}
\hline Sample ID & $\begin{array}{l}\text { Amount } \\
\text { taken(mg) }\end{array}$ & $\begin{array}{l}\text { Amount } \\
\text { observed (mg) }\end{array}$ & $\begin{array}{l}\text { Recovery } \\
\mathbf{\%}\end{array}$ \\
\hline Reference & 250 & 250 & 100 \\
CIP-PP-a & 250 & 248 & 99 \\
CIP-HP-b & 250 & 225 & 90 \\
CIP-SP-c & 250 & 258 & 103 \\
\hline
\end{tabular}

Table 5 Amount of levofloxacin determined spectrophotometerically.

\begin{tabular}{lccl}
\hline Sample ID & $\begin{array}{l}\text { Amount taken } \\
\text { (mg) }\end{array}$ & $\begin{array}{l}\text { Amount } \\
\text { observed (mg) }\end{array}$ & $\begin{array}{l}\text { Recovery } \\
\text { \% }\end{array}$ \\
\hline Reference & 250 & 250 & 100 \\
LEV-GP-d & 250 & 273 & 109 \\
LEV-OP-e & 250 & 223 & 89 \\
LEV-TP-f & 250 & 245 & 98 \\
\hline
\end{tabular}

The results shown in tables $\mathbf{3}$ and $\mathbf{4}$ indicated that the amount of drug in some cases is greater and in some is less than the reference quantity. These results could be considered in the acceptable range as according to the international standard the amount of drug in the commercial products should be within $90-110 \%$ range. However these results have illustrated that in case of multinational companies product (CIP-SP-c and LEVTP-f) result are more accurate.
Table 6 Comparison between the results determined through spectrophotometeric and HPLC method.

\begin{tabular}{lll}
\hline Sample ID & $\begin{array}{l}\text { Spectrophotometric } \\
\text { method (\% recovery) }\end{array}$ & $\begin{array}{l}\text { HPLC method } \\
\text { (\% recovery) }\end{array}$ \\
\hline CIP-PP-a & $99 \pm 0.91$ & $103 \pm 0.43$ \\
CIP-HP-b & $90 \pm 0.67$ & $92 \pm 0.73$ \\
CIP-SP-c & $103 \pm 0.43$ & $100 \pm 0.67$ \\
LEV-GP-d & $109 \pm 0.91$ & $107 \pm 0.45$ \\
LEV-OP-e & $89 \pm 0.67$ & $92 \pm 0.73$ \\
LEV-TP-f & $98 \pm 0.43$ & $99 \pm 0.67$ \\
\hline
\end{tabular}

To further check the accuracy of the results quantitative analysis was also performed using HPLC method. A comparison among the results is shown in the table 6 which showed that colorimetric method is more beneficial and advantageous due to its simplicity and low cost.

\section{CONCLUSION}

The present study described the successful development of a simple, sensitive, accurate and rapid spectrophotometeric method for the accurate determination of CIP and LEV; each one in its dosage forms using ferric (III) chloride using as the colouring reagent. The proposed method is simple, cost effective and rapid as compared to HPLC method for the determination of fluoroquinolones drugs. Moreover this method does not involve any complex procedure; complex formed instantly that show stability at $\mathrm{pH} 4$ and up to $60{ }^{\circ} \mathrm{C}$ and is free from extraction and boiling step compared to many of the previously reported procedures. Therefore, the method is practical and valuable for routine analysis in quality control laboratories for analysis of drugs in the commercial formulations.

\section{References}

[1] Bertino Jr, J. and D. Fish, Clinical therapeutics: 22 (2000) 798.

[2] Jones, R.N. and L.A. Mandell, Diagnostic microbiology and infectious disease: 44 (2002) 76.

[3] Samanidou, V.F., C. E. Demetriou, and I. N. Papadoyannis, Analytical and bio analytical chemistry: 375 (2003) 629 .

[4] Dal Bo, L., P. Mazzucchelli, and A. Marzo, Journal of Chromatography B: Biomedical Sciences and Applications: 749 (2000) 294.

[5] Hernández-Arteseros, J., et al., Journal of Chromatography: 94 (2002) 24.

[6] Fierens, C., S. Hillaert, and W. Van den Bossche, Journal of pharmaceutical and biomedical analysis: 22 (2000) 772.

[7] Gemmell, C. and V. Lorian, Antibiotics in laboratory medicine: (1996) 452.

[8] Lombardo-Agüí, M., et al., Journal of Chromatography A: (2010) 2237.

[9] Chowdary, V., N. Rao, and P. Sarma, Agricultural water management: 62 (2003) 252.

[10] Cavazos-Rocha, N., et al., Journal of chromatographic science: 52 (2014) 1281.

[11] Holtzapple, C.K., S.A. Buckley, and L.H. Stanker, Journal of Chromatography B: Biomedical Sciences and Applications: 754 (2001) 9.

[12] Michot, J.-M., et al., Antimicrobial agents and chemotherapy: 49 (2005) 2437.

[13] Mostafa, S., El-Sadek M. and A. E. Alla: Journal of pharmaceutical and biomedical analysis: 27 (2002) 142. 